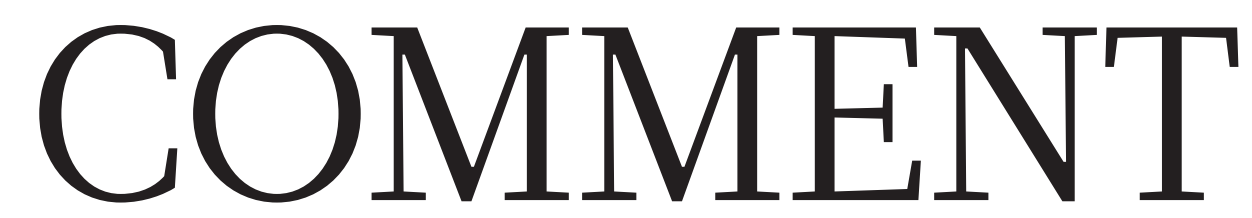

\begin{tabular}{|c|c|c|c|}
\hline $\begin{array}{l}\text { ENVIRONMENT Conservationists } \\
\text { call for a global zoning } \\
\text { exercise for roads p.308 }\end{array}$ & $\begin{array}{l}\text { HISTORY Ripping yarn of the } \\
\text { ape-man of Victorian } \\
\text { England p.310 }\end{array}$ & $\begin{array}{l}\text { EVOLUTION First biography of } \\
\text { W.D. Hamilton, the gentle } \\
\text { giant of genetics p.313 }\end{array}$ & $\begin{array}{l}\text { FUNDING Australia's grant } \\
\text { system wastes centuries of } \\
\text { researchers' time p. } \mathbf{3 1 4}\end{array}$ \\
\hline
\end{tabular}

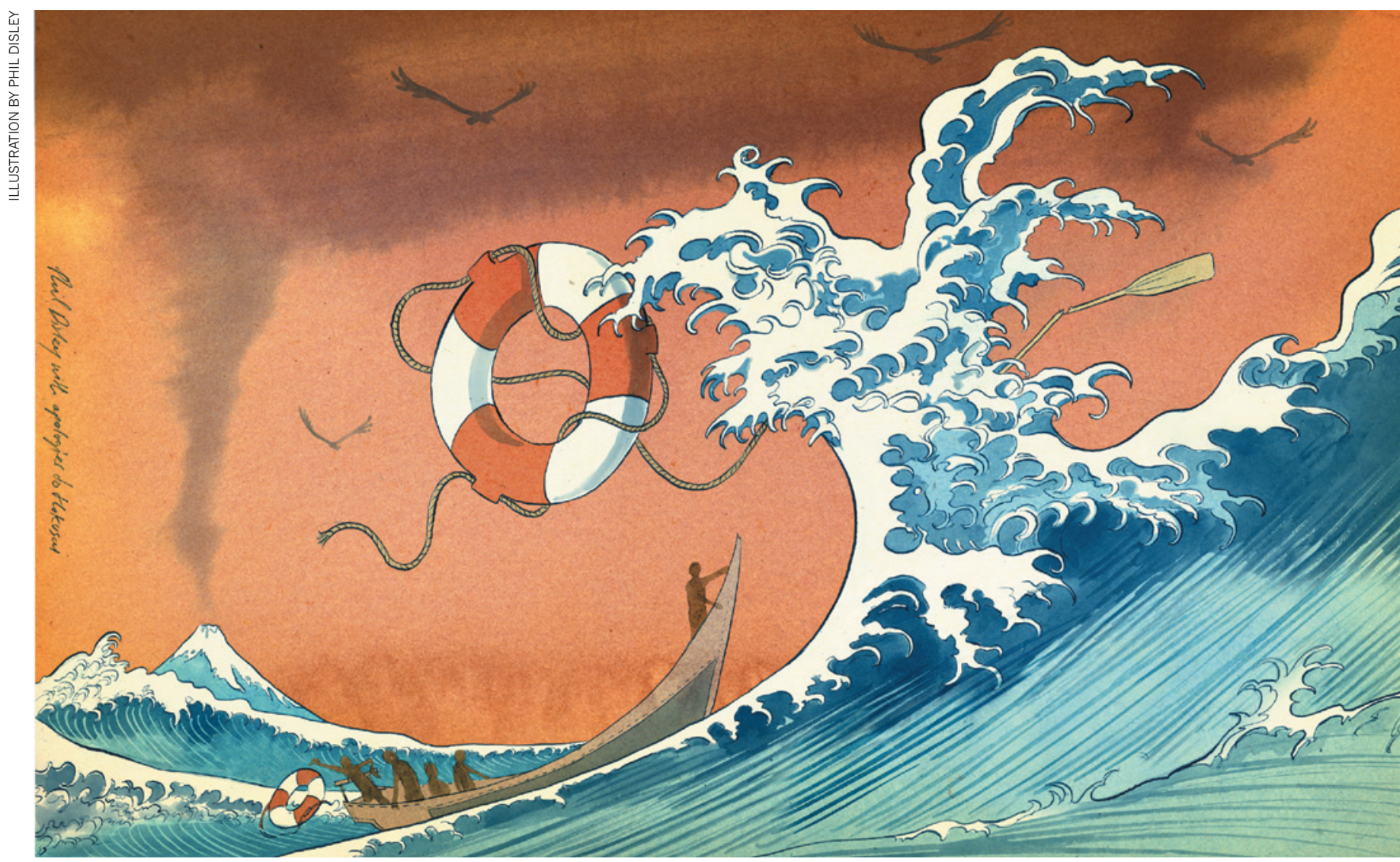

\title{
Sustainable development goals for people and planet
}

Planetary stability must be integrated with United Nations targets to fight poverty and secure human well-being, argue David Griggs and colleagues.

$\mathrm{T}$ he United Nations Rio+20 summit in Brazil in 2012 committed governments to create a set of sustainable development goals (SDGs) that would be integrated into the follow-up to the Millennium Development Goals (MDGs) after their 2015 deadline. Discussions on how to formulate these continue this week at UN headquarters in New York.

We argue that the protection of Earth's life-support system and poverty reduction must be the twin priorities for SDGs. It is not enough simply to extend MDGs, as some are suggesting, because humans are transforming the planet in ways that could undermine development gains.

As mounting research shows, the stable functioning of Earth systems - including the atmosphere, oceans, forests, waterways, biodiversity and biogeochemical cycles - is a prerequisite for a thriving global society. With the human population set to rise to 9 billion by 2050, definitions of sustainable development must be revised to include the security of people and the planet.

Defining a unified set of SDGs is challenging, especially when there can be conflict between individual goals, such as energy provision and climate-change prevention. But we show here that it is possible. By 


\section{A UNIFIED FRAMEWORK}

A set of six sustainable development goals (SDGs) follow from combining the Millennium Development Goals (MDGs) with conditions necessary to assure the stability of Earth's systems.

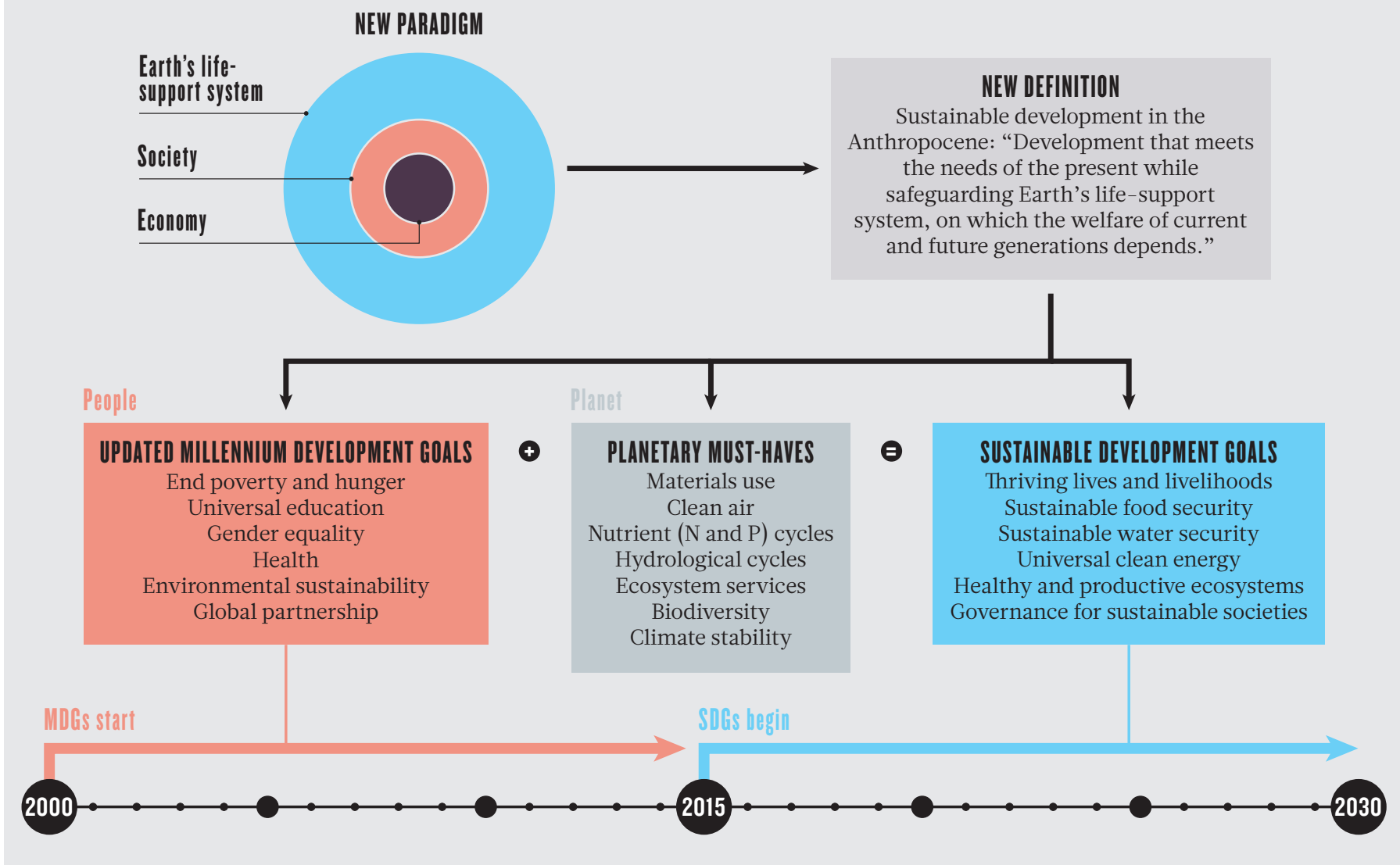

combining the MDGs with global environmental targets drawn from science and from existing international agreements, we propose six SDGs with provisional targets for 2030 .

\section{ENTER THE ANTHROPOCENE}

Since 2000, the MDGs have focused on reducing extreme poverty in developing countries. But pursuing a post-2015 agenda focused only on poverty alleviation could undermine the agenda's purpose. Growing evidence and real-world changes convincingly show that humanity is driving global environmental change and has pushed us into a new geological epoch - the Anthropocene'.

Further human pressure risks causing widespread, abrupt and possibly irreversible changes to basic Earth-system processes. Water shortages, extreme weather, deteriorating conditions for food production, ecosystem loss, ocean acidification and sea-level rise are real dangers that could threaten development and trigger humanitarian crises across the globe. Growing affluence and the right to development among the world's poor demand that people of all nations make the transition to sustainable lifestyles.

By coordinating actions internationally, SDGs can address these risks. The MDGs have shown that a goal-setting approach raises both public and policy support and channels funds effectively towards urgent global problems ${ }^{2}$. However, the political reluctance to go beyond merely extending the MDGs is a concern.

The targets for the SDGs must be measurable, based on the latest research and should apply to developed and developing countries. First, however, we need to reframe the UN paradigm of three pillars of sustainable development - economic, social and environmental - and instead view it as a nested concept. The global economy services society, which lies within Earth's life-support system. The definition of sustainable development, as laid out in the 1987 report from the UN World Commission on Environment and Development (the Brundtland Commission), should therefore be redefined to "development that meets the needs of the present while safeguarding Earth's life-support system, on which the welfare of current and future generations depends".

To set appropriate goals and targets, environmental conditions have to be identified that enable prosperous human development and set tolerable ranges for the biosphere to remain in that state. The extraordinarily stable Holocene epoch that allowed our ancestors to develop agriculture and modern societies during the past 10,000 years provides a scientific reference point. Indeed, these are the only conditions we know that can support modern life.

Building on decades of research, a 2009 analysis defined planetary boundaries which would be unsafe to transgress for nine Earth-system processes ${ }^{3}$ : climate change; rate of biodiversity loss (terrestrial and marine); interference with the nitrogen and phosphorus cycles; stratospheric ozone depletion; ocean acidification; global freshwater use; change in land use; chemical pollution; and atmospheric aerosol loading.

Adapting this planetary boundaries work, and using recent credible scientific studies and existing international processes - such as the United Nations Framework Convention on Climate Change - we extracted a 


\section{Some provisional targets for 2030}

\begin{abstract}
- Goal 1: Thriving lives and livelihoods. End poverty and improve well-being through access to education, employment and information, better health and housing, and reduced inequality while moving towards sustainable consumption and production.

This extends many targets of the Millennium Development Goals (MDGs) on poverty, health and urban environments and applies them to developed nations. It should include targets on clean air that build on World Health Organization guidelines for pollutants such as black carbon ${ }^{6}$; reductions in emissions of stratospheric ozone-depleting substances in line with projections from the Montreal Protocol; critical loads for man-made chemical compounds and toxic materials; and sustainable practices for extraction, use and recycling of scarce minerals and metals and other natural resources.
\end{abstract}

\section{- Goal 2: Sustainable food security. End hunger and achieve long-term food security - including better nutrition - through sustainable systems of production, distribution and consumption. \\ The MDG hunger target should be extended and targets added to limit nitrogen and phosphorus use in agriculture ${ }^{3,7,8}$. Nutrient- use efficiency should improve by $20 \%$ by 2020; no more than 35 million tonnes of nitrogen per year should be extracted from the}

atmosphere; phosphorus flow to the oceans should not exceed 10 million tonnes a year; and phosphorus runoff to lakes and rivers should halve by 2030 .

- Goal 3: Sustainable water security. Achieve universal access to clean water and basic sanitation, and ensure efficient allocation through integrated waterresource management.

This would contribute to MDG health targets, restrict global water runoff to less than 4000 cubic kilometres a year and limit volumes withdrawn from river basins to no more than $50-80 \%$ of mean annual flow ${ }^{3,9}$.

- Goal 4: Universal clean energy. Improve universal, affordable access to clean energy that minimizes local pollution and health impacts and mitigates global warming.

This contributes to the UN commitment to sustainable energy for all, and addresses MDG targets on education, gender equity and health. To ensure at least a $50 \%$ probability of staying within $2^{\circ} \mathrm{C}$ warming ${ }^{10}$, sustainability targets should aim for global greenhousegas emissions to peak in 2015-20, drop by $3-5 \%$ a year until 2030 , and fall by $50-80 \%$ by 2050 .

- Goal 5: Healthy and productive ecosystems. Sustain biodiversity and ecosystem services through better management, valuation, measurement, conservation and restoration.

This combines the MDG environmental targets with 2030 projections of the Aichi Targets adopted by the Convention on Biological Diversity (see www.cbd.int/sp/ targets). Extinctions should not exceed ten times the natural background rate. At least $70 \%$ of species in any ecosystem and $70 \%$ of forests should be retained. Aquatic and marine ecosystems should be managed to safeguard areas crucial for biodiversity, ecosystem services and fisheries.

- Goal 6: Governance for sustainable societies. Transform governance and institutions at all levels to address the other five sustainable development goals.

This would build on MDG partnerships and incorporate environmental and social targets into global trade, investment and finance ${ }^{4}$. Subsidies on fossil fuels and policies that support unsustainable agricultural and fisheries practices should be eliminated by 2020; product prices should incorporate social and environmental impacts. National monitoring, reporting and verification systems must be established for sustainabledevelopment targets; and open access to information and decision-making processes should be secured at all levels. list of sustainability 'must-haves' for human prosperity (see 'A unified framework').

We combined these with the MDG targets, updated and extended for 2030, to produce six SDGs: thriving lives and livelihoods, sustainable food security, sustainable water security, universal clean energy, healthy and productive ecosystems, and governance for sustainable societies (see 'Some provisional targets for 2030').

The driving principles remain: reducing poverty and hunger, improving health and well-being and creating sustainable production and consumption patterns. A goal of improving lives and livelihoods, for example, would promote sustainable access to food, water and energy while protecting biodiversity and ecosystem services.

None of this is possible without changes to the economic playing field ${ }^{4}$. National policies should, like carbon pricing, place a value on natural capital and a cost on unsustainable actions. International governance of the global commons should be strengthened, for example through binding agreements on climate change, by halting the loss of biodiversity and ecosystem services and

by addressing other sustainability concerns.

The SDG framework manages trade-offs and maximizes synergies between targets, and can be implemented from international to city scales. It integrates social, economic and environmental dimensions and provides guidance for humanity to prosper in the long term. A small number of

"None of this

is possible

without

changes to

the economic playing field."

goals is essential for focus; others could be added but should build on the core six.

There are many gaps and uncertainties in our knowledge of global environmental risks and how to enable societies to become resource-efficient, sustainable and wealthy. Research initiatives such as Future Earth, a ten-year programme coordinated by the International Council for Science ${ }^{5}$, are needed to refine targets and provide sustainable solutions for human well-being.

But the first step is for policy-makers to embrace a unified environmental and social framework for the SDGs, so that today's advances in development are not lost as our planet ceases to function for the benefit of a global population.

David Griggs is professor and director of the Monash Sustainability Institute, Monash University, Victoria 3800, Australia. Mark

Stafford-Smith, Owen Gaffney, Johan Rockström, Marcus C. Öhman, Priya Shyamsundar, Will Steffen, Gisbert Glaser, Norichika Kanie, Ian Noble.

e-mail:dave.griggs@monash.edu

1. Steffen, W. et al. Ambio 40, 739-761 (2011)

2. United Nations. The Millennium Development Goals Report 2012 (UN, 2012).

3. Rockström, J. et al. Nature 461, 472-475 (2009)

4. Biermann, F. et al. Science 335, 1306-1307 (2012).

5. Glaser, G. Nature 491, 35 (2012)

6. Shindell, D. et al. Science 335, 183-189 (2012).

7. Sutton, M. A. et al. Our Nutrient World (Centre for Ecology and Hydrology, 2013)

8. Carpenter, S. R. \& Bennett, E. M. Environ. Res. Lett. 6, 014009 (2011).

9. Smakhtin, V. U. \& Batchelor, A. L. Hydrol. Process. 19, 1293-1305 (2005).

10. Huntingford, C. et al. Environ. Res. Lett. 7, 014039 (2012).

Supplementary information and full author affiliations accompany this article online at go.nature.com/zowqiw. 